\title{
Editorial \\ Sodium Intake and Related Diseases 2.0
}

\author{
Alessandra Durazzo ${ }^{1, *}$, Ginevra Lombardi-Boccia ${ }^{1, *}$, , Antonello Santini ${ }^{2, *}$ and Massimo Lucarini ${ }^{1, *}$ \\ CREA-Research Centre for Food and Nutrition, Via Ardeatina 546, 00178 Rome, Italy \\ 2 Department of Pharmacy, University of Napoli Federico II, Via D. Montesano 49, 80131 Napoli, Italy \\ * Correspondence: alessandra.durazzo@crea.gov.it (A.D.); g.lombardiboccia@crea.gov.it (G.L.-B.); \\ asantini@unina.it (A.S.); massimo.lucarini@crea.gov.it (M.L.)
}

Citation: Durazzo, A.;

Lombardi-Boccia, G.; Santini, A.;

Lucarini, M. Sodium Intake and

Related Diseases 2.0. Int. J. Mol. Sci.

2022, 23, 170. https://doi.org/

10.3390/ijms23010170

Received: 3 December 2021

Accepted: 18 December 2021

Published: 24 December 2021

Publisher's Note: MDPI stays neutral with regard to jurisdictional claims in published maps and institutional affiliations.

Copyright: () 2021 by the authors Licensee MDPI, Basel, Switzerland. This article is an open access article distributed under the terms and conditions of the Creative Commons Attribution (CC BY) license (https:// creativecommons.org/licenses/by/ $4.0 /)$.
Many statements have been reported in literature from various sources warning of the possible risk to health connected to high salt (as sodium chloride) intake in the everyday diet, and it is increasingly pressing [1]. In general, on a worldwide basis, most of the adult population consumes between 8 and $15 \mathrm{~g}$ of salt per day, when the WHO recommends a value of less than $5 \mathrm{~g}$ per day [2].

It is well known that high dietary sodium can induce a rise in blood pressure (BP) but, independent of a change in BP it may also cause target organ damage, with direct effects on the brain, heart, kidneys, vasculature, skin, and bone, contributing to disease development over time [3,4].

The mechanisms underlying sodium-induced health consequences are not yet completely understood, but they could involve alterations in organs' function through common mediators of the target organ dysfunction, including heightened inflammation and oxidative stress.

Hyseni et al. [5], in a systematic review on dietary salt reduction policies, remarked on how comprehensive strategies involving multiple components (reformulation, food labeling, and media campaigns) and "upstream" population-wide policies, e.g., mandatory reformulation, generally appear to achieve larger reductions in population-wide salt consumption than "downstream", individually focused interventions.

It is worth mentioning a paper tackling salt consumption outside the home [6]. Ali et al. [7] reviewed the application of mobile health technologies aimed at salt reduction.

Among recent studies, the paper of Dodd et al. [8], published in Advances in Nutrition, presents a systematic review of the evident effectiveness and feasibility of taxing salt and foods high in sodium. Modeling suggests that taxing all foods based on their salt content is likely to have more impact than taxing specific products high in salt, given that salt is pervasive in the food chain. Further research is needed in this direction [8].

Donfrancesco et al. [9] reported the trend of salt intake measured by a 24-h urine collection in the Italian adult population between 2008 and 2018 in the framework of the CUORE project surveys. The average daily salt intake of the general Italian adult population remains higher than the WHO recommended level, but a significant reduction of $12 \%$ in men and $13 \%$ in women has occurred over the past ten years.

A current cluster-randomized controlled trial study protocol carried out in a rural area of Bangladesh by Islam et al. [10] reported a lowering of blood pressure through changing lifestyle by means of a motivational education program.

The recent review of Zhang et al. [11] studied and reported how excessive consumption of high-sodium foods during COVID-19 presents an underappreciated public health risk.

This second edition of the proposed Special Issue is specifically aimed at gathering and assessing recent research on the molecular-level mechanisms of the relationship between sodium intake and related diseases; e.g., studies of the role of sodium in the physiological processes, with a focus on the mechanisms of action, are welcome. 
Author Contributions: A.D., G.L.-B., A.S. and M.L. have made a substantial, direct, and intellectual contribution to the work and approved it for publication. All authors have read and agreed to the published version of the manuscript.

Funding: This research received no external funding.

Conflicts of Interest: The authors declare no conflict of interest.

\section{References}

1. Lucarini, M.; Durazzo, A.; Sette, S.; Lombardi-Boccia, G.; Santini, A.; Strazzullo, P. Sodium Intake and Related Diseases. Int. J. Mol. Sci. 2021, 22, 7608. [CrossRef]

2. WHO. Salt Reduction. Available online: https://www.who.int/news-room/fact-sheets/detail/salt-reduction\#: \{\}:text=For\%20 adults $\% 3 \mathrm{~A} \% 20 \mathrm{WHO} \% 20$ recommends $\% 20$ that, relative $\% 20$ to $\% 20$ those $\% 20$ of $\% 20$ adults (accessed on 30 November 2021).

3. Farquhar, W.B.; Edwards, D.G.; Jurkovitz, C.T.; Weintraub, W.S. Dietary sodium and health: More than just blood pressure. J. Am. Coll. Cardiol. 2015, 65, 1042-1050. [CrossRef] [PubMed]

4. Robinson, A.T.; Edwards, D.G.; Farquhar, W.B. The Influence of Dietary Salt Beyond Blood Pressure. Curr. Hypertens Rep. 2019, 21, 42. [CrossRef] [PubMed]

5. Hyseni, L.; Elliot-Green, A.; Lloyd-Williams, F.; Cappuccio, F.P.; Capewell, S. Systematic review of dietary salt reduction policies: Evidence for an effectiveness hierarchy? PLoS ONE 2017, 12, e0177535. [CrossRef] [PubMed]

6. Caraher, M.; Hughes, N. Tackling salt consumption outside the home. BMJ 2019, 364, 1108. [CrossRef] [PubMed]

7. Ali, S.H.; Luo, R.; Li, Y.; Tang, C.; Zhang, P. Application of mobile health technologies aimed at salt reduction: Systematic review. JMIR mHealth uHealth 2019, 7, e13250. [CrossRef] [PubMed]

8. Dodd, R.; Santos, J.A.; Tan, M.; Osornprasop, S.; Webster, J. Effectiveness and Feasibility of Taxing Salt and Foods High in Sodium: A Systematic Review of the Evidence. Adv. Nutr. 2020, 11, 1616-1630. [CrossRef] [PubMed]

9. Donfrancesco, C.; Lo Noce, C.; Russo, O.; Palmieri, L.; Strazzullo, P. Trend of salt intake measured by 24-h urine collection in the Italian adult population between the 2008 and 2018 CUORE project surveys. Nutr. Metab. Cardiov. Dis. 2021, 31, 802-813. [CrossRef]

10. Islam, F.M.A.; Lambert, E.A.; Islam, S.M.S.; Thompson, B.; Lambert, G.W. Lowering blood pressure by changing lifestyle through a motivational education program: A cluster randomized controlled trial study protocol. Trials 2021, 22, 438. [CrossRef] [PubMed]

11. Zhang, X.; Chen, B.; Jia, P.; Han, J. Locked on salt? Excessive consumption of high-sodium foods during COVID-19 presents an underappreciated public health risk: A review. Environ. Chem. Lett. 2021, 19, 3583-3595. [CrossRef] [PubMed] 